Article

\title{
A Two-Source Model for Estimating Evaporative Fraction (TMEF) Coupling Priestley-Taylor Formula and Two-Stage Trapezoid
}

\author{
Hao Sun \\ College of Geoscience and Surveying Engineering, China University of Mining and Technology, \\ Beijing 100083, China; sunhao@cumtb.edu.cn; Tel.: +86-10-6233-9355 \\ Academic Editors: Jose Moreno, Richard Gloaguen and Prasad S. Thenkabail \\ Received: 10 December 2015; Accepted: 11 March 2016; Published: 16 March 2016
}

\begin{abstract}
Remotely sensed land surface temperature and fractional vegetation coverage (LST/FVC) space has been widely used in modeling and partitioning land surface evaporative fraction (EF) which is important in managing water resources. However, most of such models are based on conventional trapezoid and simply determine the wet edge as air temperature $\left(T_{\mathrm{a}}\right)$ or the lowest LST value in an image. We develop a new Two-source Model for estimating EF (TMEF) based on a two-stage trapezoid coupling with an extension of the Priestly-Taylor formula. Latent heat flux on the wet edge is calculated with the Priestly-Taylor formula, whereas that on the dry edge is set to 0 . The wet and dry edges are then determined by solving radiation budget and energy balance equations. The model was evaluated by comparing with other two models that based on conventional trapezoid (i.e., the Two-source Trapezoid Model for Evapotranspiration (TTME) and a One-source Trapezoid model for EF (OTEF)) in how well they simulate and partition EF using MODIS products and field observations from HiWATER-MUSOEXE in 2012. Results show that the TMEF outperforms the other two models, where EF mean absolute relative deviations are $9.57 \%$ (TMEF), $15.03 \%$ (TTME), and $30.49 \%$ (OTEF).
\end{abstract}

Keywords: evaporative fraction; evapotranspiration; two-source model; land surface temperature; fractional vegetation coverage

\section{Introduction}

Modeling and partitioning land surface evapotranspiration (ET) are of crucial importance in managing water resource both at the farm and the irrigation project level [1,2]. They are also essential in predicting the climatic response of ecosystem functions and processes [3-5]. Evaporative fraction (EF), defined as a ratio between the latent heat flux and the available energy at the land surface, is an index for ET. It has been widely used to characterize the energy partition over land surfaces and to infer daily energy balance information based on mid-day remote sensing measurements [3,6-9]. Moreover, it is more suitable as an index for surface moisture condition or drought status than ET, because ET is not only a function of the land surface conditions but also the surface available energy $[1,10]$.

Satellite remote sensing offers the possibility to obtain regional distributed EF or ET in a relatively cheap and rapid way [2]. Recently, remote sensing-based EF or ET models have experienced an explosive growth. Among them, the models based on the land surface temperature and fractional vegetation coverage (LST/FVC) space show a wide application prospect because these models can avoid complex parameterization of aerodynamic and surface resistances for water and heat transfer [11] and enable the calculation of EF or ET from a remote sensing image itself without additional information [3,12]. Moreover, Yang et al. (2015) compared three two-source remote sensing models of ET (i.e., the Hybrid dual-source scheme and Trapezoid framework-based ET Model (HTEM), 
the Two-Source Energy Balance (TSEB) model, and the MOD16 ET algorithm) and found that the HTEM which is based on the LST/FVC space outperformed the other two models in estimating and partitioning ET [13].

Currently, there are two typical classes of EF models based on the LST/FVC space: the one-source models and the two-source models. Generally, the one-source models utilize the LST/FVC space to interpolate the effective Priestly-Taylor parameter in the Priestly-Taylor formula for calculating EF $[3,6,8,14,15]$, whereas the two-source models use the LST/FVC space to decompose LST into vegetation and soil component temperatures $\left(T_{\mathrm{V}}\right.$ and $\left.T_{\mathrm{S}}\right)$ and subsequently calculate $\mathrm{EF}$ and its vegetation and soil components $\left(\mathrm{EF}_{\mathrm{v}}\right.$ and $\left.\mathrm{EF}_{\mathrm{S}}\right)$ [16-18]. The one-source models assume land surface as a single uniform layer which produce significant errors when applied to partially vegetated landscapes [18]. In contrast, the two-source models treat soil and vegetation as independent sources of the moisture flux and are generally considered to be an advancement of the one-source models [18]. Moreover, the two-source models are able to discriminate vegetation transpiration from soil surface evaporation. Vegetation transpiration and soil evaporation are controlled by different biotic and physical processes. Discriminating them is critical to many environmental applications and water management [5].

However, most of such two-source models e.g., the Two-source Trapezoid Model for Evapotranspiration (TTME) [17] and the HTEM [18] are based on the conventional trapezoidal LST/FVC space which assumes that $T_{\mathrm{v}}$ and $T_{\mathrm{S}}$ vary simultaneously with the variation of soil moisture availability. Sun (2015) demonstrated that $T_{\mathrm{v}}$ should vary after $T_{\mathrm{S}}$ because vegetation can absorb deep soil moisture to maintain transpiration [19]. A two-stage trapezoidal LST/FVC space was then suggested to take into account the variation speed difference between $T_{\mathrm{V}}$ and $T_{\mathrm{S}}$ [19]. Additionally, the wet edge of the LST/FVC space is usually assumed to be horizontal and determined as the air temperature $\left(T_{\mathrm{a}}\right)[17,18]$ or the lowest temperature in an image [20]. Long and Singh (2012) indicated that derivation of the wet edge from satellite imagery suffers somewhat from subjectivity [17]. Errors caused by clouds and terrains can lead to an inappropriate specification of the lowest temperature. Determining the wet edge temperature as $T_{a}$, however, is also inappropriate because it implies that EF on the wet edge is a constant value of 1, but EF is controlled not only by the availability of water but also by $T_{\mathrm{a}}$ and wind speed [6]. Yang et al. (2015) indicated that the underestimation of temperatures for the wet edge is a main reason for underestimating EF in the HTEM model [13]. Therefore, a new way is required to determine the wet edge.

To advance the performances in modeling and partitioning EF or ET based on LST/FVC space, a new Two-source Model for estimating EF (TMEF) is constructed in this study. The TMEF model is based on the two-stage trapezoidal LST/FVC space rather than the conventional trapezoid. Moreover, the TMEF model determines the wet edge in a theoretical way through calculating latent heat flux on the wet edge with the Priestly-Taylor formula. Finally, it combines the Priestly-Taylor formula and the two-stage trapezoid to simulate $\mathrm{EF}_{\mathrm{v}}, \mathrm{EF}_{\mathrm{s}}$, and $\mathrm{EF}$.

\section{Methods}

\subsection{Model Formulation}

\subsubsection{Priestly-Taylor Formula and Its Extension}

The rate of ET is mainly controlled by the available energy, the availability of water, and other factors affecting the mechanism to transport water from the land surface to the atmosphere such as wind speed and air temperature. Priestley and Taylor (1972) simplified the general form of ET for surfaces with sufficient water supply [21]:

$$
\mathrm{LE}=\alpha_{\mathrm{PT}}\left[\left(\mathrm{R}_{\mathrm{n}}-\mathrm{G}\right) \frac{\Delta}{\Delta+\gamma}\right]
$$


where LE is latent heat flux $\left(\mathrm{W} / \mathrm{m}^{2}\right) ; \mathrm{R}_{\mathrm{n}}$ is net radiation $\left(\mathrm{W} / \mathrm{m}^{2}\right) ; \mathrm{G}$ is soil heat flux $\left(\mathrm{W} / \mathrm{m}^{2}\right), \alpha_{\mathrm{PT}}$ is the original Priestley-Taylor's parameter; $\Delta$ is the gradient of the saturated vapor pressure to the air temperature and $\gamma$ is the psychometric constant. Jiang and Islam $(1999,2001)[8,14]$ extended the Priestley-Taylor formula to a range of surface conditions:

$$
\mathrm{EF}=\frac{\mathrm{LE}}{\mathrm{R}_{\mathrm{n}}-\mathrm{G}}=\phi \frac{\Delta}{\Delta+\gamma}
$$

where $\phi$ is a complex effective Priestley-Taylor parameter. It is noteworthy that parameter $\phi$, although it looks similar to the $\alpha_{\mathrm{PT}}$, encompasses a wide range evaporative conditions and can take a range of values [8,14]. Jiang and Islam (2001) suggested a two-step interpolation scheme to obtain the $\phi$ value using a triangular LST/FVC space [8]. In that scheme, $\phi$ has the minimum value $\phi_{\min }$ on the dry edge and the maximum value $\phi_{\max }$ on the wet edge of the triangular LST/FVC space. Moreover, $\phi_{\max }$ was considered equaling to $(\Delta+\gamma) / \Delta$ and $\phi_{\min }$ was determined as a linear function of NDVI [8]. Stisen $e t$ al. (2008) tried to improve the determination of the $\phi_{\min }$ by proposing a non-linear method [15].

However, trapezoidal LST/FVC space is different from the triangular LST/FVC space. The dry edge of the triangular LST/FVC space is not an isopleth of zero evapotranspiration but a zero isopleth for soil evaporation [22]. In contrast, the dry edge of the trapezoidal LST/FVC space represents an isopleth of zero evapotranspiration $[17,19]$. Thus, the EF is equal to 0 i.e., $\phi_{\min }$ should equal to 0 on the dry edge of the trapezoidal LST/FVC space [17]. In addition, EF should not be a constant value of 1 i.e., $\phi_{\max }$ should not equal to $(\Delta+\gamma) / \Delta$ on the wet edge of the triangular or trapezoidal LST/FVC space because EF is controlled not only by the availability of water but also by air temperature and wind speed [6]. The original Priestley-Taylor formula was proposed to express the evaporation rate from an extensive wet surface. It can be used to determine EF on the wet edge of the trapezoidal LST/FVC space. Resultantly, $\phi_{\max }$ is set to the parameter $\alpha_{\mathrm{PT}}$ in this study. Previous studies have shown that the parameter $\alpha_{\mathrm{PT}}$ varies depending upon the differences in meteorological conditions [23]. However, an overall mean value of 1.26 for typically observed atmospheric conditions is well accepted in many studies and it is relatively insensitive to small changes in atmospheric parameters $[3,6,8,14,24,25]$. Thus, the value of 1.26 is adopted in this study for determining $\alpha_{\mathrm{PT}}$.

\subsubsection{Two-Stage Trapezoid Model}

Figure 1 presents the theoretical diagram of the conventional trapezoidal and the two-stage trapezoidal LST/FVC spaces where point B and A represent bare soil with the maximum and minimum evaporation, and points $C$ and $D$ represent fully vegetation with the maximum and minimum transpiration, respectively. AD is the dry edge and BC is the wet edge of the LST/FVC space. The LST at the point $A$ and $D$ are denoted as $T_{\mathrm{S}}{ }^{\max }$ and $T_{\mathrm{V}}{ }^{\max }$. The LST at point B and $\mathrm{C}$ are $T_{\mathrm{S}} \min$ and $T_{\mathrm{V}}{ }^{\mathrm{min}}$. There are two distinct differences between the conventional trapezoid and the two-stage trapezoid:

(1) Firstly, the isopleth of the soil moisture availability from the wet edge to the dry edge has only one variation stage in the conventional trapezoid, whereas it has two variation stages in the two-stage trapezoid. In conventional trapezoid, $T_{\mathrm{S}}$ and $T_{\mathrm{V}}$ change simultaneously as land surface dries. However, in two-stage trapezoid, $T_{\mathrm{S}}$ changes in the first stage and $T_{\mathrm{V}}$ changes in the next stage, which considers the variation speed difference between $T_{\mathrm{S}}$ and $T_{\mathrm{V}}$ in view of that vegetation can absorb deep soil moisture to maintain transpiration [19].

(2) Secondly, the EF on the wet edge of the conventional trapezoid is set to a constant value of 1 [17]. Contrarily, the EF on the wet edge of the two-stage trapezoid is set to $\alpha_{\mathrm{PT}} \times \Delta /(\Delta+\gamma)$ in this study. The EF on the dry edges are both equal to 0 . Resultantly, the conventional trapezoid and the two-stage trapezoid have the same theoretical expressions for the dry edge which have been presented in previous literatures $[17,26]$. However, they have different expressions for the wet edge. The wet edge was usually expressed as equaling to $T_{\mathrm{a}}$ in conventional trapezoid $[12,20]$. In this study, we would present a theoretical expression of the wet edge in two-stage trapezoid. 

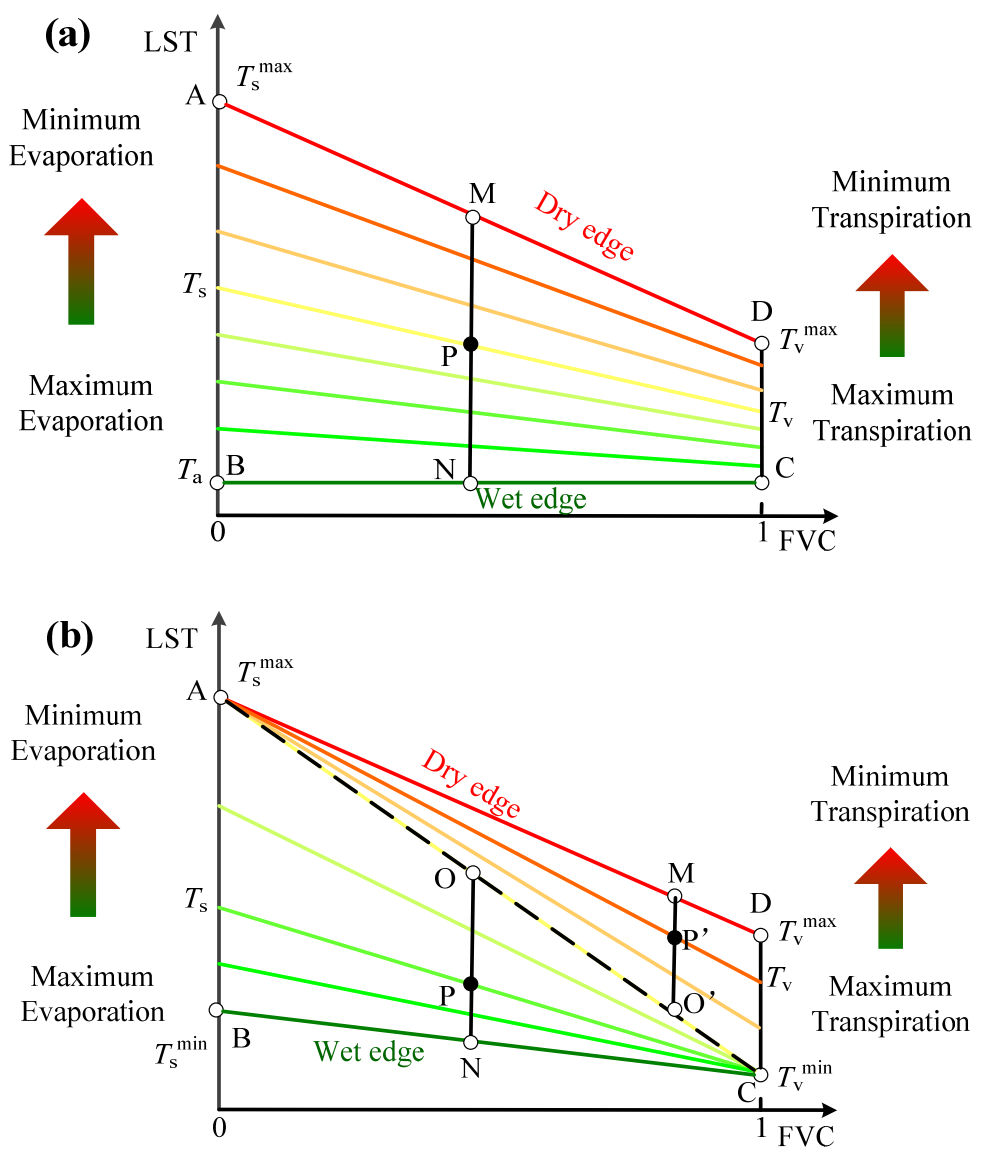

Figure 1. (a) the conventional trapezoidal LST/FVC space derived from [17]; (b) the two-stage trapezoidal LST/FVC space.

For land surfaces on the wet edge, LE is determined by the Equation (1) and the other components of surface energy budget are determined by:

$$
\begin{gathered}
\mathrm{R}_{\mathrm{n}}=(1-\alpha) \times S_{\mathrm{d}}+\varepsilon \times \varepsilon_{\mathrm{a}} \times \sigma \times T_{\mathrm{a}}^{4}-\varepsilon \times \sigma \times \mathrm{LST}^{4} \\
\mathrm{H}=\rho c_{p} \frac{\mathrm{LST}-\mathrm{T}_{\mathrm{a}}}{r_{\mathrm{a}}} \\
\mathrm{G}=n \times \mathrm{R}_{\mathrm{n}}
\end{gathered}
$$

where $\alpha$ and $\varepsilon$ are land surface albedo and emissivity; $S_{\mathrm{d}}$ is the down-welling shortwave radiation $\left(\mathrm{W} / \mathrm{m}^{2}\right) ; \varepsilon_{\mathrm{a}}$ is atmosphere emissivity which can be determined using the method provided in [7]; $\sigma$ is a constant with a value of $5.67 \times 10^{-8} \mathrm{~W} / \mathrm{m}^{2} / \mathrm{K}^{4} . \rho$ is the air density $\left(1.293 \mathrm{Kg} / \mathrm{m}^{3}\right) ; C_{p}$ is the air specific heat at the constant pressure $(1005.0 \mathrm{~J} / \mathrm{kg} / \mathrm{K}) ; r_{a}$ is the aerodynamic resistance $(\mathrm{s} / \mathrm{m}) ; n$ is a fraction coefficient.

Consequently, the following equations are obtained according to surface energy balance equation:

$$
(1-n)\left(1-\alpha_{\mathrm{PT}} \frac{\Delta}{\Delta+\gamma}\right)\left[(1-\alpha) \times S_{\mathrm{d}}+\varepsilon \times \varepsilon_{\mathrm{a}} \times \sigma \times T_{\mathrm{a}}^{4}-\varepsilon \times \sigma \times \mathrm{LST}^{4}\right]=\rho c_{p} \frac{\mathrm{LST}-\mathrm{T}_{\mathrm{a}}}{r_{\mathrm{a}}}
$$

In order to calculate from the Equation (6), the first two terms of the Taylor series of $\mathrm{LST}^{4}$ at $T_{\mathrm{a}}$ are selected to approximate $\mathrm{LST}^{4}$.

$$
\mathrm{LST}^{4} \approx T_{\mathrm{a}}{ }^{4}+4 T_{\mathrm{a}}{ }^{3}\left(\mathrm{LST}-T_{\mathrm{a}}\right)=4 T_{\mathrm{a}}{ }^{3} \mathrm{LST}-3 T_{\mathrm{a}}{ }^{4}
$$

Finally, the $T_{\mathrm{S}}{ }^{\min }$ and $T_{\mathrm{V}}{ }^{\min }$ can be witten as: 


$$
\left\{\begin{array}{c}
T_{\mathrm{s}}^{\min }=\frac{3 a_{\mathrm{s}} T_{\mathrm{a}}^{4}-e_{\mathrm{s}}}{4 a_{\mathrm{s}} T_{\mathrm{a}}^{3}+d_{\mathrm{s}}} \\
T_{\mathrm{v}}{ }^{\min }=\frac{3 a_{\mathrm{v}} T_{\mathrm{a}}^{4}-e_{\mathrm{V}}}{4 a_{\mathrm{v}} T_{\mathrm{a}}{ }^{3}+d_{\mathrm{v}}}
\end{array}\right.
$$

with the coefficients $a_{\mathrm{S}}=\varepsilon_{\mathrm{s}} \times \sigma ; a_{\mathrm{v}}=\varepsilon_{\mathrm{v}} \times \sigma ; d_{\mathrm{s}}=\rho c_{p} /\left\{r_{\mathrm{a}}^{\mathrm{s}}\left(1-n_{\mathrm{s}}\right)\left[1-\alpha_{\mathrm{PT}} \Delta /(\Delta+\gamma)\right]\right\} ;$ $d_{\mathrm{v}}=\rho c_{p} /\left\{r_{\mathrm{a}}{ }^{\mathrm{v}}\left(1-n_{\mathrm{v}}\right)\left[1-\alpha_{\mathrm{PT}} \Delta /(\Delta+\gamma)\right]\right\} ; e_{\mathrm{S}}=-\varepsilon_{\mathrm{s}} \times \varepsilon_{\mathrm{a}} \times \sigma \times T_{\mathrm{a}}{ }^{4}-d_{\mathrm{s}} T_{\mathrm{a}}-\left(1-\alpha_{\mathrm{s}}\right) \times S_{\mathrm{d}} ;$ and $e_{\mathrm{V}}=-\varepsilon_{\mathrm{v}} \times \varepsilon_{\mathrm{a}} \times \sigma \times T_{\mathrm{a}}^{4}-d_{\mathrm{v}} T_{\mathrm{a}}-\left(1-\alpha_{\mathrm{v}}\right) \times S_{\mathrm{d}}$ where $\varepsilon_{\mathrm{v}}$ and $\varepsilon_{\mathrm{s}}$ are emissivities (unitless) of vegetation and soil components, respectively; $\alpha_{\mathrm{v}}$ and $\alpha_{\mathrm{s}}$ are the albedo for the vegetation and soil components (unitless); $r_{\mathrm{a}}{ }^{\mathrm{s}}$ and $r_{\mathrm{a}}{ }^{\mathrm{v}}$ are the aerodynamic resistances $(\mathrm{s} / \mathrm{m})$ for the soil and vegetation components, respectively; $n_{\mathrm{S}}$ and $n_{\mathrm{v}}$ are the fractional coefficients between $\mathrm{G}$ and $\mathrm{R}_{\mathrm{n}}$ for the soil and vegetation components and they are set as 0.35 and 0 as done in [17]; $\Delta$ and $\gamma$ can be determined using several empirical methods, but for convenience they are calculated using an approximate formula that $\Delta /(\Delta+\gamma)=0.0127 \times T_{\mathrm{a}}+0.3464[6]$.

In a similar vein, the $T_{\mathrm{S}}{ }^{\max }$ and $T_{\mathrm{v}}{ }^{\max }$ can be written as:

$$
\left\{\begin{array}{c}
T_{\mathrm{s}}{ }^{\max }=\frac{3 a_{\mathrm{s}}{ }^{\prime} T_{\mathrm{a}}{ }^{4}-e_{\mathrm{s}}{ }^{\prime}}{4 a_{\mathrm{s}}{ }^{\prime} T_{\mathrm{a}}{ }^{3}+d_{\mathrm{s}}{ }^{\prime}} \\
T_{\mathrm{v}}{ }^{\max }=\frac{3 a_{\mathrm{v}}{ }^{\prime} T_{\mathrm{a}}^{4}-e_{\mathrm{v}}{ }^{\prime}}{4 a_{\mathrm{v}}{ }^{\prime} T_{\mathrm{a}}{ }^{3}+d_{\mathrm{v}}{ }^{\prime}}
\end{array}\right.
$$

with the coefficients $a_{\mathrm{s}}{ }^{\prime}=\varepsilon_{\mathrm{s}} \times \sigma ; a_{\mathrm{v}}{ }^{\prime}=\varepsilon_{\mathrm{v}} \times \sigma ; d_{\mathrm{s}}{ }^{\prime}=\rho c_{p} /\left[r_{\mathrm{a}}^{\mathrm{s}}\left(1-n_{\mathrm{s}}\right)\right] ; d_{\mathrm{v}}{ }^{\prime}=\rho c_{p} /\left[r_{\mathrm{a}} \mathrm{v}\left(1-n_{\mathrm{v}}\right)\right]$; $e_{\mathrm{s}}{ }^{\prime}=-\varepsilon_{\mathrm{s}} \times \varepsilon_{\mathrm{a}} \times \sigma \times T_{\mathrm{a}}{ }^{4}-d_{\mathrm{s}}{ }^{\prime} T_{\mathrm{a}}-\left(1-\alpha_{\mathrm{s}}\right) \times S_{\mathrm{d}} ; e_{\mathrm{v}}{ }^{\prime}=-\varepsilon_{\mathrm{v}} \times \varepsilon_{\mathrm{a}} \times \sigma \times T_{\mathrm{a}}{ }^{4}-d_{\mathrm{v}}{ }^{\prime} T_{\mathrm{a}}-\left(1-\alpha_{v}\right) \times S_{\mathrm{d}}$.

In this study, $r_{\mathrm{a}}{ }^{\mathrm{s}}$ and $r_{\mathrm{a}}{ }^{\mathrm{v}}$ are determined using the method suggested in [17]. Moreover, In the calculation of $r_{\mathrm{a}}{ }^{\mathrm{s}}$ and $r_{\mathrm{a}}{ }^{\mathrm{v}}$, the underdetermined $T_{\mathrm{s}}{ }^{\min }, T_{\mathrm{v}}{ }^{\min }, T_{\mathrm{s}}{ }^{\max }$ and $T_{\mathrm{V}}{ }^{\max }$ are required as input. Therefore, iterative algorithm is necessary in the calculation of Equations (8) and (9). We set the initial values of $T_{\mathrm{S}}{ }^{\min }, T_{\mathrm{v}}{ }^{\min }, T_{\mathrm{S}}{ }^{\max }$ and $T_{\mathrm{v}}{ }^{\max }$ as $T_{\mathrm{a}}$ in the iteration cycle.

\subsubsection{Coupling Priestly-Taylor Formula with Two-Stage Trapezoid for Estimating EF}

We proposed the TMEF model for estimating EF based on the combination between the Priestly-Taylor formula and the two-stage trapezoid model. Firstly, let's denote a random pixel as point $\mathrm{P}$ when it locates in the lower triangle and denote it as point $\mathrm{P}^{\prime}$ when it locates in the upper triangle of the two-stage trapezoid as shown in Figure 1b. Point $\mathrm{N}$ and $\mathrm{O}$ locate at the wet edge $\mathrm{BC}$ and the median line AC, respectively, which have the same $f_{\mathrm{v}}$ with the point P. Point $\mathrm{M}$ and $\mathrm{O}^{\prime}$ locate at the dry edge $\mathrm{AD}$ and the median line $\mathrm{AC}$, respectively, which have the same $f_{\mathrm{v}}$ with the point $\mathrm{P}^{\prime}$.

Subsequently, $\mathrm{EF}_{\mathrm{S}}$ and $\mathrm{EF}_{\mathrm{v}}$ for the point $\mathrm{P}$ are calculated by the following equation.

$$
\left\{\begin{aligned}
\mathrm{EF}_{\mathrm{S}} & =\frac{\mathrm{LST}_{\mathrm{O}}-\mathrm{LST}_{\mathrm{P}}}{\mathrm{LST}_{\mathrm{O}}-\mathrm{LST}_{\mathrm{N}}} \times \alpha_{\mathrm{PT}} \times \frac{\Delta}{\Delta+\gamma} \\
\mathrm{EF}_{\mathrm{v}} & =\alpha_{\mathrm{PT}} \times \frac{\Delta}{\Delta+\gamma}
\end{aligned}\right.
$$

where $\mathrm{LST}_{\mathrm{O}}, \mathrm{LST}_{\mathrm{P}}, \mathrm{LST}_{\mathrm{N}}$, are the LST at point $\mathrm{O}, \mathrm{P}$, and $\mathrm{N}$, respectively. $\mathrm{LST}_{\mathrm{O}}$ and $\mathrm{LST}_{\mathrm{N}}$ are determined using a linear interpolation i.e., $\mathrm{LST}_{\mathrm{O}}=\left(T_{\mathrm{V}}{ }^{\min }-T_{\mathrm{S}}{ }^{\max }\right) f_{\mathrm{V}}{ }^{\mathrm{P}}+T_{\mathrm{S}}{ }^{\max }$ and $\mathrm{LST}_{\mathrm{N}}=\left(T_{\mathrm{V}}{ }^{\min }-T_{\mathrm{s}}{ }^{\min }\right) f_{\mathrm{V}}{ }^{\mathrm{P}}+T_{\mathrm{s}}{ }^{\min } \cdot f_{\mathrm{V}}{ }^{\mathrm{P}}$ is the FVC at point $\mathrm{P}$.

For the point $\mathrm{P}^{\prime}, \mathrm{EF}_{\mathrm{S}}$ and $\mathrm{EF}_{\mathrm{v}}$ are calculated by the following equation.

$$
\left\{\begin{array}{l}
\mathrm{EF}_{\mathrm{S}}=0 \\
\mathrm{EF}_{\mathrm{v}}=\frac{\mathrm{LST}_{\mathrm{M}}-\mathrm{LST}_{\mathrm{P}^{\prime}}}{\mathrm{LST}_{\mathrm{M}}-\mathrm{LST}_{\mathrm{O}^{\prime}}} \times \alpha_{\mathrm{PT}} \times \frac{\Delta}{\Delta+\gamma}
\end{array}\right.
$$


where $\mathrm{LST}_{\mathrm{M}}, \mathrm{LST}_{\mathrm{P}^{\prime}}, \mathrm{LST}_{\mathrm{O}^{\prime}}$ are the LST at point $\mathrm{M}, \mathrm{P}^{\prime}$, and $\mathrm{O}^{\prime}$, respectively. $\mathrm{LST}_{\mathrm{M}}$ and $\mathrm{LST}_{\mathrm{O}^{\prime}}$ are also determined using the linear interpolation i.e., $\mathrm{LST}_{\mathrm{M}}=\left(T_{\mathrm{V}}{ }^{\max }-T_{\mathrm{S}}{ }^{\max }\right) \times f_{\mathrm{V}}{ }^{\mathrm{P}^{\prime}}+T_{\mathrm{S}}{ }^{\max }$ and $\mathrm{LST}_{\mathrm{O}^{\prime}}=\left(T_{\mathrm{V}} \min -T_{\mathrm{S}}^{\max }\right) f_{\mathrm{V}} \mathrm{P}^{\prime}+T_{\mathrm{S}} \max \cdot f_{\mathrm{V}} \mathrm{P}^{\prime}$ is the FVC at point $\mathrm{P}^{\prime}$.

Finally, the TMEF model adopts a two-source scheme to represent the relationship between the EF for a mixed landscape and the EF for vegetation and soil components [17]:

$$
\mathrm{EF}=\frac{\mathrm{LE}}{\mathrm{Q}}=f_{\mathrm{v}} \times \frac{\mathrm{Q}_{\mathrm{v}}}{\mathrm{Q}} \times \mathrm{EF}_{\mathrm{v}}+\left(1-f_{\mathrm{v}}\right) \times \frac{\mathrm{Q}_{\mathrm{s}}}{\mathrm{Q}} \times \mathrm{EF}_{\mathrm{s}}
$$

where $f_{v}$ is the FVC; $Q$ is the available energy $\left(W / m^{2}\right)$ defined as the difference between $R_{n}$ and $G ; Q_{v}$ and $Q_{s}$ as the vegetation and soil components of $Q$. $Q$ and its components are determined using the following equation.

$$
\left\{\begin{array}{l}
\mathrm{Q}_{\mathrm{v}}=\left(1-n_{\mathrm{v}}\right) \times \mathrm{R}_{\mathrm{n}}{ }^{\mathrm{v}}=\left(1-n_{\mathrm{v}}\right) \times\left[\left(1-\alpha_{\mathrm{v}}\right) S_{\mathrm{d}}+\varepsilon_{\mathrm{v}} \varepsilon_{\mathrm{a}} \sigma T_{\mathrm{a}}{ }^{4}-\varepsilon_{\mathrm{v}} \sigma T_{\mathrm{v}}{ }^{4}\right] \\
\mathrm{Q}_{\mathrm{s}}=\left(1-n_{\mathrm{s}}\right) \times \mathrm{R}_{\mathrm{n}}{ }^{\mathrm{s}}=\left(1-n_{\mathrm{s}}\right) \times\left[\left(1-\alpha_{\mathrm{s}}\right) S_{\mathrm{d}}+\varepsilon_{\mathrm{s}} \varepsilon_{\mathrm{a}} \sigma T_{\mathrm{a}}{ }^{4}-\varepsilon_{\mathrm{s}} \sigma T_{\mathrm{S}}{ }^{4}\right] \\
\mathrm{Q}=f_{\mathrm{v}} \times \mathrm{Q}_{\mathrm{v}}+\left(1-f_{\mathrm{v}}\right) \times \mathrm{Q}_{\mathrm{s}}
\end{array}\right.
$$

where $T_{\mathrm{v}}$ and $T_{\mathrm{S}}$ of the point $\mathrm{P}$ are determined as:

$$
\left\{\begin{array}{l}
T_{\mathrm{S}}=T_{\mathrm{S}}{ }^{\max }-\frac{\mathrm{LST}_{\mathrm{O}}-\mathrm{LST}_{\mathrm{P}}}{\mathrm{LST}_{\mathrm{O}}-\mathrm{LST}_{\mathrm{N}}} \times\left(T_{\mathrm{S}}^{\max }-T_{\mathrm{S}}^{\min }\right) \\
T_{\mathrm{V}}=T_{\mathrm{V}}^{\min }
\end{array}\right.
$$

$T_{\mathrm{V}}$ and $T_{\mathrm{S}}$ of the point $\mathrm{P}^{\prime}$ are determined as:

$$
\left\{\begin{array}{l}
T_{\mathrm{S}}=T_{\mathrm{S}}{ }^{\max } \\
T_{\mathrm{V}}=T_{\mathrm{V}}{ }^{\max }-\frac{\mathrm{LST}_{\mathrm{M}}-\mathrm{LST}_{\mathrm{P}^{\prime}}}{\mathrm{LST}_{\mathrm{M}}-\mathrm{LST}_{\mathrm{O}^{\prime}}} \times\left(T_{\mathrm{v}}{ }^{\mathrm{max}}-T_{\mathrm{V}}{ }^{\min }\right)
\end{array}\right.
$$

\subsection{Model Evaluation}

The TMEF model was firstly evaluated by comparing the EF estimations with the EF observations over all testing sites. Evaluation indices include Pearson correlation coefficient $(r)$, Root Mean Square Error (RMSE), Relative Deviation (RD), and Mean Absolute Relative Deviation (MARD). The relative deviation is expressed as:

$$
\mathrm{RD}=\frac{\mathrm{EF}^{\prime}-\mathrm{EF}}{\mathrm{EF}} \times 100 \%
$$

where $\mathrm{EF}$ represents the observed value and $\mathrm{EF}^{\prime}$ represents the estimated value.

Additionally, there are two typical models that utilize the trapezoidal LST/FVC space to model EF. Both of them are based on the conventional trapezoid as shown in Figure 1a. One of them does not use the Priestley-Taylor whereas uses the relative change of $T_{\mathrm{S}}$ and $T_{\mathrm{V}}$ to the dry edge and wet edge to calculate $\mathrm{EF}$ [17]. TTME is a representative of such model where $\mathrm{EF}_{\mathrm{s}}$ and $\mathrm{EF}_{\mathrm{v}}$ are expressed as:

$$
\left\{\begin{array}{l}
\mathrm{EF}_{\mathrm{s}}=\frac{T_{\mathrm{s}}{ }^{\max }-T_{\mathrm{s}}}{T_{\mathrm{s}}{ }^{\max }-T_{\mathrm{a}}} \times \frac{Q_{\mathrm{s}, 0}}{Q_{\mathrm{s}}} \\
\mathrm{EF}_{\mathrm{v}}=\frac{T_{\mathrm{v}}{ }^{\max }-T_{\mathrm{v}}}{T_{\mathrm{v}}{ }^{\max }-T_{\mathrm{a}}} \times \frac{Q_{\mathrm{v}, 0}}{Q_{\mathrm{v}}}
\end{array}\right.
$$

where $Q_{\mathrm{s}, 0}$ and $Q_{\mathrm{v}, 0}$ are calculated by the Equation (13) when $T_{\mathrm{s}}=T_{\mathrm{a}}$ and $T_{\mathrm{v}}=T_{\mathrm{a}}$. For another typical model, the conventional trapezoidal LST/FVC space is employed to interpolate the effective 
Priestley-Taylor parameter [1]. Taking a random pixel $\mathrm{P}$ for example in the LST/FVC space as illustrated in Figure 1a, its EF is calculated by:

$$
\mathrm{EF}=\frac{\mathrm{LST}_{\mathrm{M}}-\mathrm{LST}_{\mathrm{P}}}{\mathrm{LST}_{\mathrm{M}}-\mathrm{LST}_{\mathrm{N}}} \times \alpha_{\mathrm{PT}} \times \frac{\Delta}{\Delta+\gamma}
$$

This model is denoted as One-source Trapezoid model for EF (OTEF) in this study. The TMEF, TTME, and OTEF models were compared with each other in how well they model EF at each site. Evaluation indexes include Pearson-r and RMSE. Additionally, the differences of estimated $\mathrm{EF}_{\mathrm{v}}$ and $\mathrm{EF}_{\mathrm{s}}$ between the TMEF model and the TTME model were also evaluated.

\section{Study Area and Materials}

\subsection{Study Area}

Zhangye oasis, located in the middle reaches of the Heihe River Basin, the second largest inland river basin in China, is selected as the study area. As a kernel experimental area of the project Heihe Watershed Allied Telemetry Experimental Research (HiWATER) and its subproject Multiscale Observation Experiment on Evapotranspiration (MUSOEXE) [27], several observation sties were established in this study area according to the crop structure, shelterbelt, residential area, soil moisture, and irrigation status for measuring the surface fluxes of momentum, energy, and water vapor in $2012[28,29]$. At each site, an automatic weather station and an eddy covariance (EC) system were installed. Observations at six sites in the corn field were obtained in this study from the "Heihe Plan Science Data Center, National Natural Science Foundation of China". Figure 2 shows the kernel experimental area over oasis surfaces and the spatial distribution of the six sites. More information about these observations can be found in several papers [28,30-32].

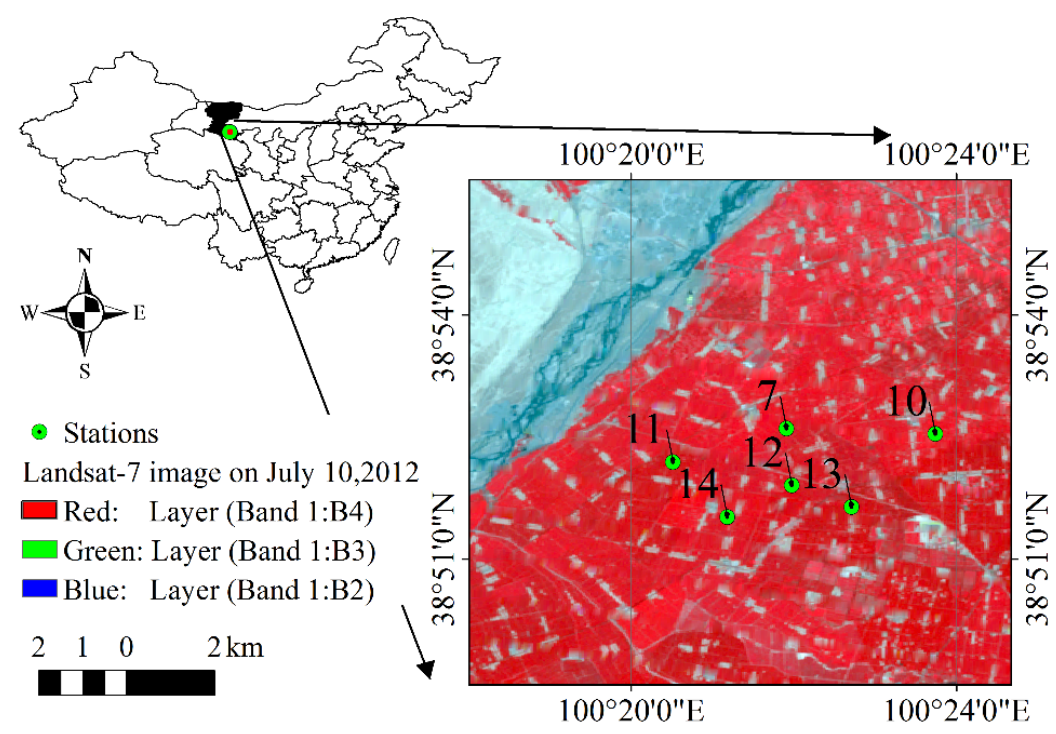

Figure 2. Spatial distribution of the testing sites.

\subsection{Study Materials}

Several meteorological parameters were measured from June to September in 2012 by the sites listed in Figure 2. Six parameters among them are eligible for our study including near surface air temperature $T_{\mathrm{a}}\left({ }^{\circ} \mathrm{C}\right)$, air relative humidity $\mathrm{RH}(\%)$, solar down welling shortwave radiation $S_{\mathrm{d}}\left(\mathrm{W} / \mathrm{m}^{2}\right)$, friction velocity $u_{*}(\mathrm{~m} / \mathrm{s})$, sensible heat flux $\mathrm{H}\left(\mathrm{W} / \mathrm{m}^{2}\right)$, and latent heat flux $\mathrm{LE}\left(\mathrm{W} / \mathrm{m}^{2}\right)$. The $\mathrm{H}$ and LE measured using the EC system were used to determine EF observations since they have been corrected for closure using the Bowen ratio closure method $[28,29,33]$. 
Additionally, four MODIS products covering the period from April to October in 2012 were collected in this study. They are Land Surface Temperature/Emissivity Daily L3 Global 1km products (MOD11A1 and MYD11A1) and Vegetation Indices 16-Day L3 Global 1km product (MOD13A2 and MYD13A2). The criterions "Pixel produced", "good data quality", "average emissivity error $\leqslant 0.02$ ", and "average LST error $\leqslant 2 \mathrm{~K}^{\prime}$ " were used to control LST data. Additionally, the VI usefulness parameter in the SVI products Quality Assessment Science Data Sets was used to control NDVI data. The NDVI data with a VI usefulness from 0000 (highest quality) to 1100 (lowest quality) were retained in this study, while the others were excluded. It is noteworthy that that LST and NDVI have different temporal resolution, daily for LST and 16 days for NDVI. The 16-day NDVI were interpolated firstly into 8-day NDVI and subsequently daily NDVI during the 8-day interval were assumed to be invariant as done in $[34,35]$. MODIS NDVI was utilized to calculate $f_{\mathrm{v}}$ by the equation that

$$
f_{v}=\left[\left(\mathrm{NDVI}-\mathrm{NDVI}_{\min }\right) /\left(\mathrm{NDVI}_{\max }-\mathrm{NDVI}_{\min }\right)\right]^{2}
$$

where $\mathrm{NDVI}_{\min }$ is the NDVI corresponding to bare soil and NDVI $\mathrm{I}_{\max }$ is the NDVI for fully vegetated area. In this study, $\mathrm{NDVI}_{\min }$ and $\mathrm{NDVI}_{\max }$ were set as 0.2 and 0.86 as done in the paper [3]. Additionally, $\varepsilon_{\mathrm{s}}$ and $\varepsilon_{\mathrm{v}}$ were set as 0.95 and $0.98 ; \alpha_{\mathrm{v}}$ and $\alpha_{\mathrm{s}}$ were set as 0.18 and 0.24 ; and the vegetation height $\left(h_{\mathrm{c}}\right)$ was set as $1.0 \mathrm{~m}$ according to the field observations over the study area [36].

\section{Results}

\subsection{Model Evaluation}

Comparison of the estimated EF with the observed EF at all flux towers is illustrated in Figure 3. The totality number $(\mathrm{N})$ of the comparison samples is 438 . The comparison results indicate that there is a significant correlation between the observed EF and the estimated EF by the TMEF model with an $r$ value of 0.69 at the level of 0.05 by the two-tailed test. The $r$ values of the TTME and the OTEF models are 0.46 and 0.62 , respectively, both of which are smaller than the $r$ value of the TMEF model. Moreover, the RMSE of the TMEF model is 0.10, which is less than that of the TTME (0.15) and the OTEF (0.27) models. Figure $3 b$ shows the frequency histogram of the relative deviation between the estimated and the observed EF. Results indicate that the EF estimated by the TMEF model has the minimum MARD with a value of $9.57 \%$, whereas the MARD of the TTME and OTEF models are $15.03 \%$ and $30.49 \%$, respectively. In summary, Figure 3 indicates that the TMEF model shows the best results in estimating EF as compared at all flux towers.
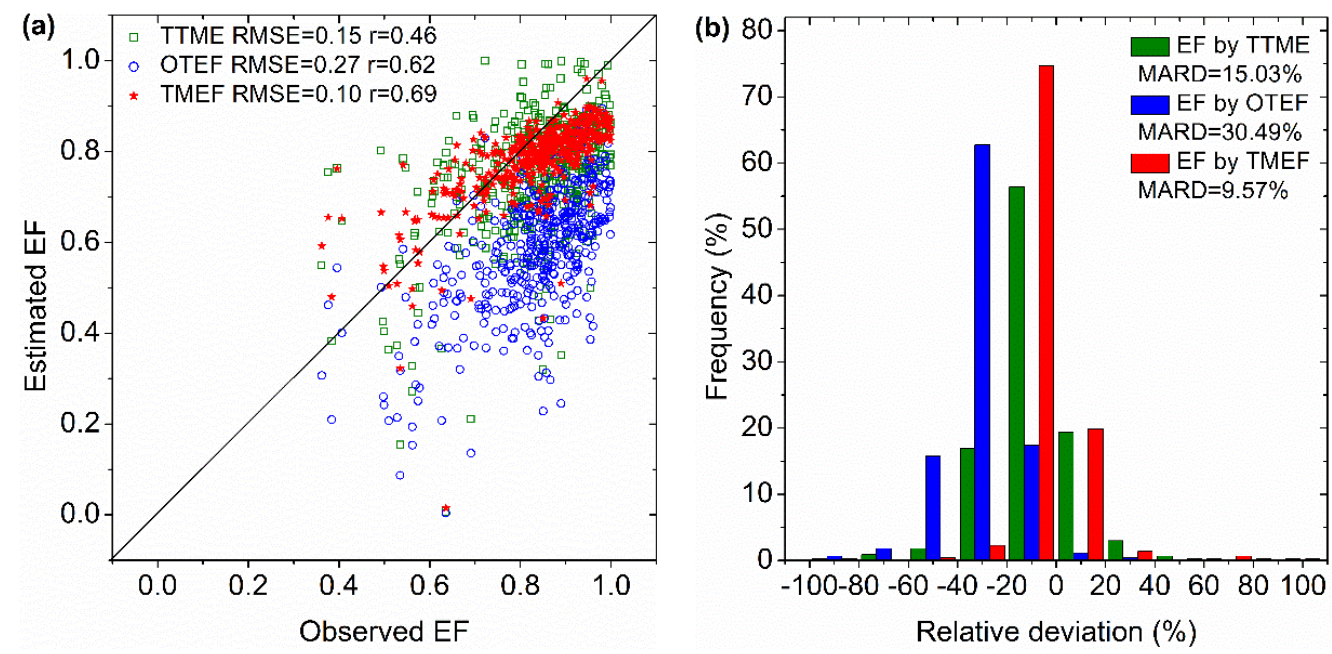

Figure 3. Comparison of the estimated EF with observed EF at all stations in (a) scatter plot and (b) frequency histogram of the relative deviation. 
Comparisons of the suggested TMEF model with the TTME and the OTEF models at each flux tower are presented in Figure 4. The results indicate that RMSE of the TMEF model is less than that of other models at all of the testing sites. Moreover, the $r$ value of the TMEF model is significantly greater than that of other models at all of the testing sites. Consequently, the suggested TMEF model presents the best effectiveness in estimating EF as compared with the TTME and the OTEF models at each flux tower.
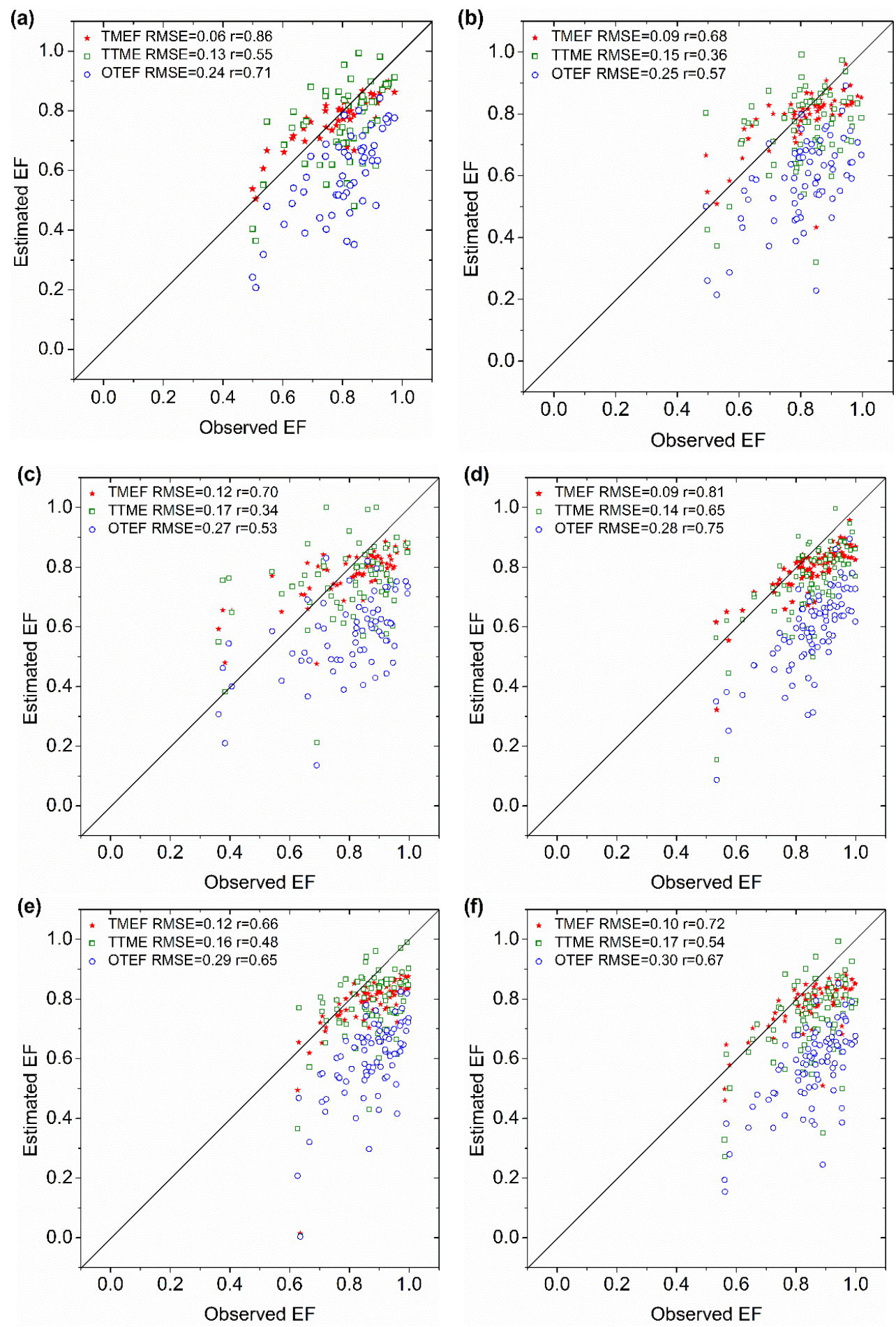

Figure 4. Comparison of estimated EF between the TMEF, TTME, and OTEF models where (a-f) corresponds to the flux sites of NO. 7, NO.10 No. 14 . 
In addition, the differences of estimated $\mathrm{EF}_{\mathrm{V}}$ and $\mathrm{EF}_{\mathrm{S}}$ between the TMEF model and the TTME model are presented in Figure 5. The soil moisture at the depth of $40 \mathrm{~cm}$, which is closely correlated with the water availability for vegetation transpiration in the study area, experienced several variation processes from wet to dry during the period from DOY (day of year) 165 to DOY 260 in 2012. However, the soil moisture maintains a relative higher status approximately at $25 \%$. The soil type in the study area is silt loam and its field capacity is approximate to $30 \%$ [37]. Therefore, there is almost no water stress occurred on vegetation during that period, which indicates that the $\mathrm{EF}_{\mathrm{v}}$ should maintain at a relative higher status. Results in Figure 5 show that the $\mathrm{EF}_{\mathrm{V}}$ by the TMEF model varied around 0.7 0.8 with a relatively flat variation, whereas the $\mathrm{EF}_{\mathrm{v}}$ by the TTME model has a more unsteady variation within $0.5-1.0$.
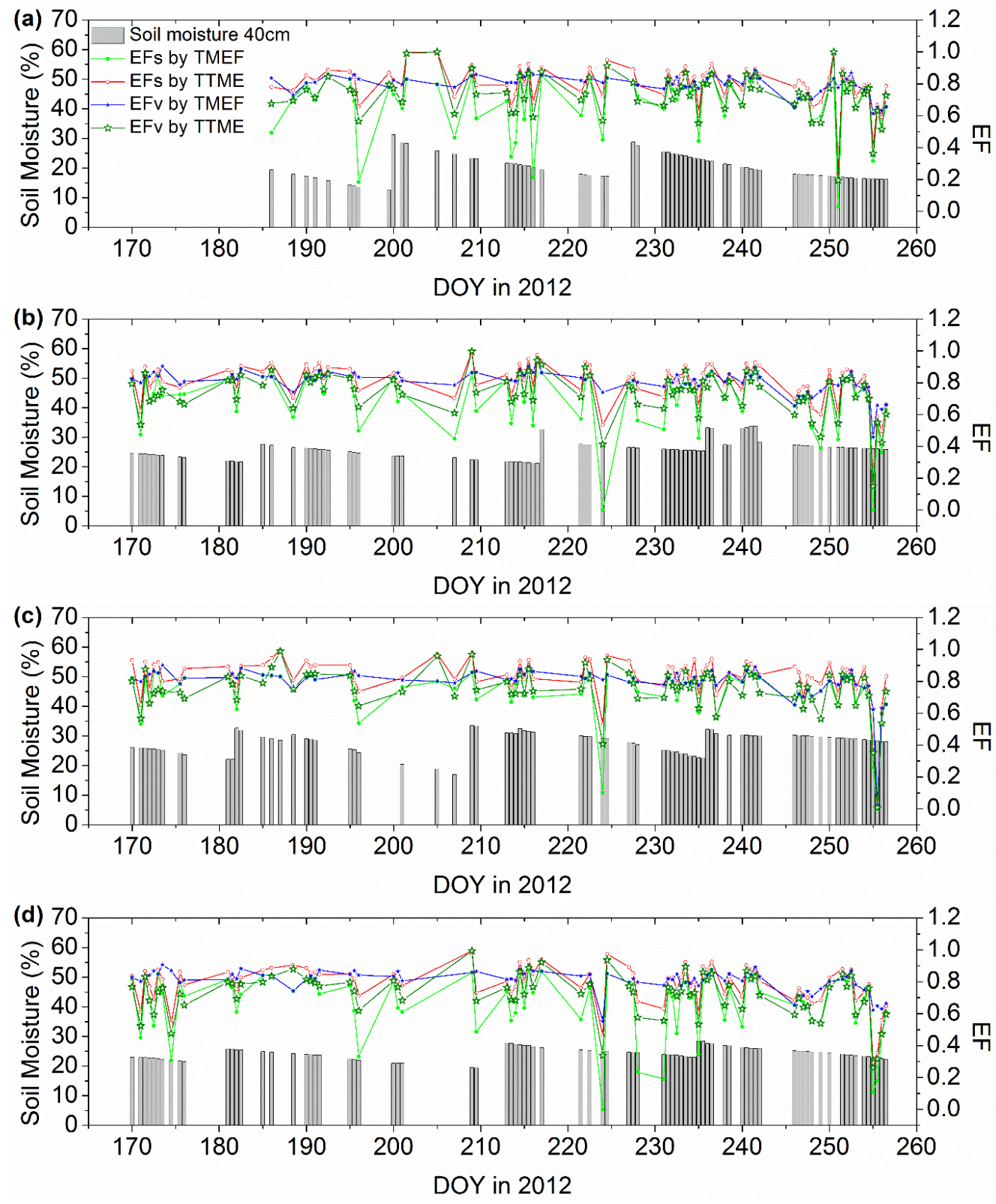

Figure 5. Comparison of estimated EFs and EFv between the TMEF and the TTME models at (a) No.11; (b) No.12; (c) No.13; and (d) No.14 stations.

Furthermore, Figure 5 shows several variation processes of soil from wet to dry at the depth of $40 \mathrm{~cm}$. The soil at the surface would suffer a more drastic variation during that period. In most times, 
soil moisture at the vegetation root zone is greater than the soil moisture at skin surface. Resultantly, the $\mathrm{EF}_{\mathrm{S}}$ should be less than the $\mathrm{EF}_{\mathrm{v}}$ most of the time. Figure 5 indicates that the $\mathrm{EF}_{\mathrm{S}}$ is less than the $\mathrm{EF}_{\mathrm{V}}$ by the TMEF model in most times, whereas the $\mathrm{EF}_{\mathrm{S}}$ is greater than the $\mathrm{EF}_{\mathrm{v}}$ by the TTME model most times. In summary, Figure 5 demonstrates that the TMEF model is more effectiveness than the TTME in partitioning $\mathrm{EF}$.

\subsection{Sensitivity Analysis}

Model sensitivity analysis plays an important role in understanding the mechanisms of error propagation and uncertainty of the model. In this study, we compared the relative change of a new estimated EF to its initial EF with the relative change of a new input variable to its initial value. The selected variables are LST, $T_{\mathrm{a}}, \alpha_{\mathrm{s}}, \alpha_{\mathrm{v}}, \mu_{*}, \varepsilon_{\mathrm{a}}$, and $h_{\mathrm{c}}$ in order to compare with the TTME [17], where LST and $T_{\mathrm{a}}$ varied in (LST $\left.-2 \mathrm{~K}, \mathrm{LST}+2 \mathrm{~K}\right)$ and $\left(T_{\mathrm{a}}-2 \mathrm{~K}, T_{\mathrm{a}}+2 \mathrm{~K}\right)$ with a step size of $0.5 \mathrm{~K}$. The other parameters varied in $\pm 20 \%$ of their initial values with a step size of $5 \%$. Two initial scenes are selected to analyze the sensitivity according to the position of a pixel in the two-stage trapezoidal LST/FVC space. The two initial scenes are constructed based on the environment at the overpass time of Terra MODIS at the site of NO. 10 on DOY 250, 2012. Their variables and parameters are presented in Table 1. Figure 6 presents the position of the pixels in the two-stage trapezoidal LST/FVC space. Scene 1 corresponds to the pixels varied within the lower triangular space $\mathrm{ABC}$, however, Scene 2 corresponds to the pixels varied within the upper triangular space ACD.

Table 1. Parameters of the initial scenes for sensitivity analysis.

\begin{tabular}{|c|c|c|c|c|c|c|c|c|c|c|c|}
\hline Parameters & NDVI & LST (K) & $T_{\mathrm{a}}\left({ }^{\circ} \mathrm{C}\right)$ & $\varepsilon_{\mathbf{a}}$ & $S_{d}\left(W / m^{2}\right)$ & $u_{*}(\mathrm{~m} / \mathrm{s})$ & $\alpha_{\mathrm{s}}$ & $\alpha_{\mathrm{v}}$ & $\varepsilon_{\mathrm{S}}$ & $\varepsilon_{\mathrm{V}}$ & $h_{\mathrm{c}}(\mathrm{m})$ \\
\hline $\begin{array}{l}\text { Scene } 1 \\
\text { Sche? }\end{array}$ & $\begin{array}{l}0.65 \\
0.80\end{array}$ & 307 & 22.67 & 0.63 & 798.8 & 0.24638 & 0.24 & 0.18 & 0.95 & 0.98 & 1.0 \\
\hline
\end{tabular}
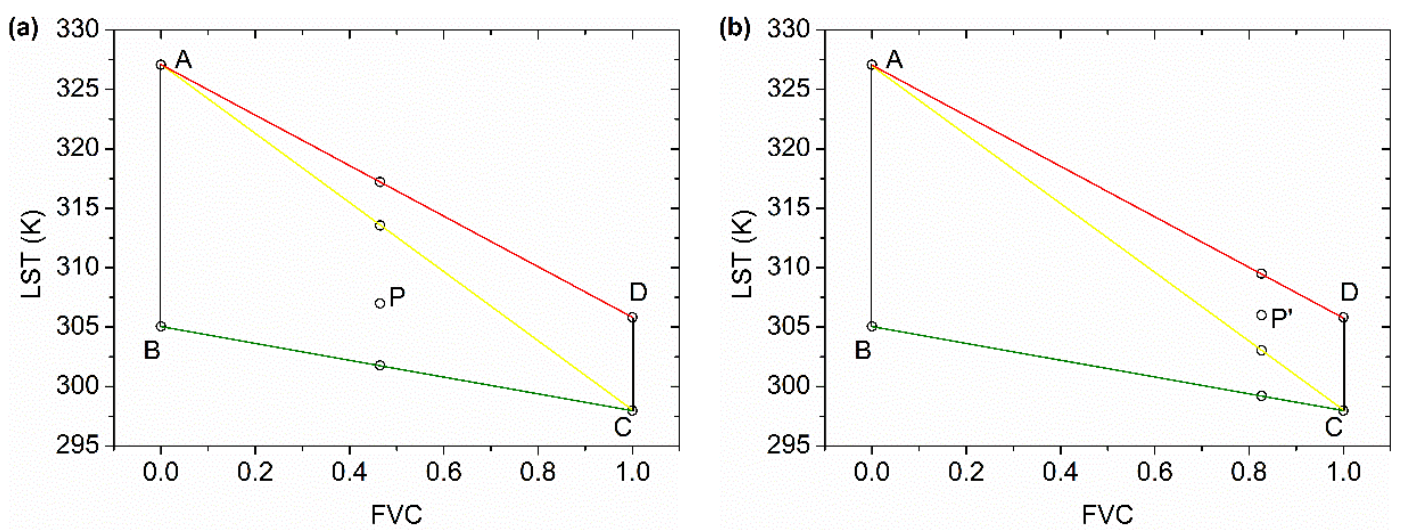

Figure 6. The two-stage trapezoidal LST/FVC spaces corresponded to different scenes where (a) corresponds to the Scene 1 and (b) corresponds to Scene 2.

Figure 7 shows the results of the sensitivity analysis. Firstly, Figure 7a, a' show that $\alpha_{\mathrm{S}}$ and $\alpha_{\mathrm{v}}$ are both negatively correlated with the EF estimates in the two scenes. With increasing albedo, the net radiation will be reduced and therefore LE/EF tend to be reduced [17]. In Scene 1, a 20\% increase in $\alpha_{\mathrm{S}}$ and $\alpha_{\mathrm{V}}$ can result in $1.66 \%$ and $0.85 \%$ decreases in the EF estimates, whereas that increase can result in $12.91 \%$ and $6.81 \%$ decreases in Scene 2.

Secondly, Figure $7 \mathrm{~b}, \mathrm{~b}^{\prime}$ indicates that $\mu_{*}$ and $h_{\mathrm{c}}$ are negatively correlated with the EF estimates, and $\varepsilon_{\mathrm{a}}$ is positively correlated with the EF estimates. In Scene 1, a $20 \%$ increase in $\varepsilon_{\mathrm{a}}$ only result in $3.55 \%$ increase in EF estimates, whereas that increase in $\varepsilon_{\mathrm{a}}$ would lead to a $27.19 \%$ increase in EF estimates in Scene 2. Moreover, a $20 \%$ increase in $\mu_{*}$ and $h_{\mathrm{c}}$ lead to $5.34 \%$ and $0.27 \%$ decreases in EF estimates for Scene 1 and 28.42\% and 13.84\% decreases in EF estimates for Scene 2. 
Thirdly, Figure $7 \mathrm{c}, \mathrm{c}^{\prime}$ indicate that LST is negatively correlated with EF, but $T_{\mathrm{a}}$ is positively correlated with EF. A $2 \mathrm{~K}$ increase in LST and $T_{\mathrm{a}}$ would result in $5.60 \%$ decrease and $7.92 \%$ increase in EF estimates for Scene 1. However, a $2 \mathrm{~K}$ increase in LST and $T_{\mathrm{a}}$ would result in $57.04 \%$ decrease and $53.66 \%$ increase in EF estimates for Scene 2.

Sensitivity analysis performed by Long and Singh (2012) indicated that a $2 \mathrm{~K}$ increase in LST and $T_{\mathrm{a}}$ and a $20 \%$ increase in $\alpha_{\mathrm{s}}, \alpha_{\mathrm{v}}, \mu_{*}, h_{\mathrm{c}}$, and $\varepsilon_{\mathrm{a}}$ could result in a $28.6 \%$ decrease, a $27.6 \%$ increase, a $3.3 \%$ decrease, a $1.3 \%$ decrease, a $12.2 \%$ decrease, a $1.4 \%$ decrease, and a $3.1 \%$ increase, respectively, in the LE estimates from TTME model. The proposed TMEF model show less sensitivity than the TTME model when land surface is in Scene 1 environment. Additionally, the TMEF model show greater sensitivity than the TTME when land surface is in the Scene 2 environment. For Scene 1, pixels locate in the lower triangular space of the two-stage trapezoidal LST/FVC space and vegetation holds the status without water stress. For Scene 2, pixels locate in the upper triangular space of the two-stage trapezoid and the vegetation suffers water stress.
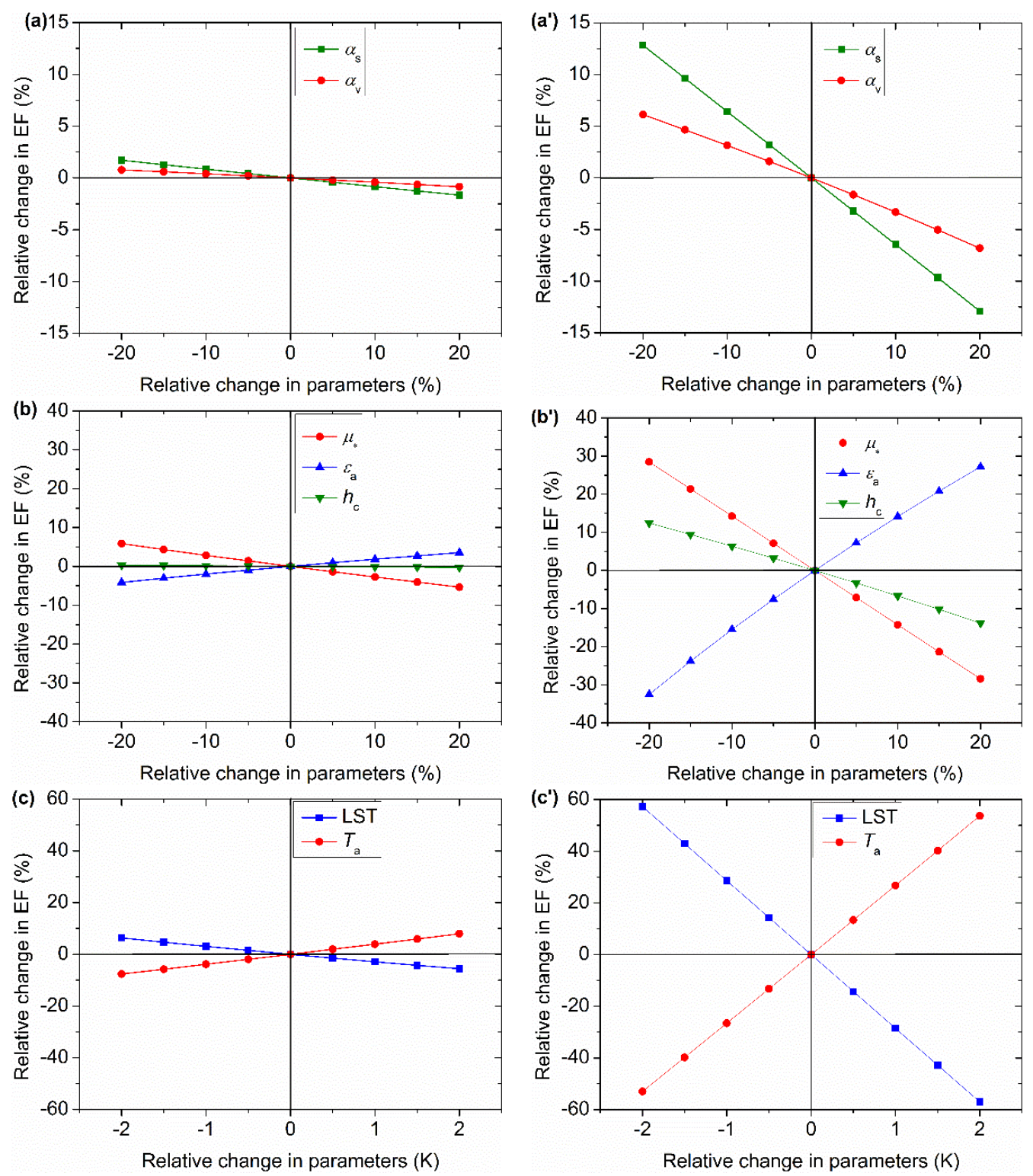

Figure 7. Sensitivity analysis of TMEF to $\alpha_{\mathrm{S}}$ and $\alpha_{\mathrm{v}}$ in Scene 1 (a) and Scene $2\left(\mathbf{a}^{\prime}\right), \mu_{*}, \varepsilon_{\mathrm{a}}$, and $h_{\mathrm{c}}$ in Scene $1(\mathbf{b})$ and Scene $2\left(\mathbf{b}^{\prime}\right)$, and LST and $T_{\mathrm{a}}$ in Scene $1(\mathbf{c})$ and Scene $2\left(\mathbf{c}^{\prime}\right)$. 
In summary, TMEF is most sensitive to LST and $T_{\mathrm{a}}$. Constraining errors of TMEF lies in controlling uncertainties in the LST and $T_{\mathrm{a}}$ data. TMEF shows less sensitivity to the variables than TTME in the environment that vegetation is not subjected to water stress. Contrarily, TMEF is more sensitive to the variables than TTME in the environment that vegetation suffers water stress. The TMEF requires higher data quality of the input variables when vegetation suffers water stress.

\section{Discussion}

The proposed TMEF model has three unique advantages as compared with the same type models that based on LST/FVC space.

Firstly, the TMEF provides a theoretical way to determine the wet edge of LST/FVC space. In some literatures, the wet edge is assumed to be horizontal and determined as $T_{a}$, which implies that EF is a constant value of 1 on the wet edge $[8,14,17,18]$. However, the wet edge only represents the surface with the maximum soil moisture availability and EF is not only correlated with water availability but also correlated with environmental factors such as the air temperature. In the TMEF model, latent heat flux on the wet edge is calculated with the Priestly-Taylor formula. The wet edge is then determined by solving radiation budget and energy balance equations. Figure 6 shows an example where the wet edge is determined by the theoretical way. The result indicates that the wet edge is not necessarily horizontal and it has a higher temperature than $T_{\mathrm{a}}$. Yang et al. (2015) evaluated the HTEM model that based on the conventional trapezoidal LST/FVC space and found that HTEM tends to underestimate ET due mostly to the underestimation of temperatures for the wet edge. This problem can be solved by the theoretical way of determining wet edge suggested in the TMEF model.

Secondly, the TMEF is based on the two-stage trapezoidal space rather than the conventional trapezoidal space. The conventional trapezoidal LST/FVC space assumes $T_{\mathrm{S}}$ and $T_{\mathrm{V}}$ change simultaneously as land surface dries. However, there is variation speed difference between $T_{\mathrm{S}}$ and $T_{\mathrm{V}}$ in most times and areas [19]. The two-stage trapezoidal LST/FVC space considers the variation speed difference. However, the two-stage trapezoid would become invalid when the variation speed difference between $T_{\mathrm{S}}$ and $T_{\mathrm{v}}$ is not significant or even inverse. For example, a sudden irrigation or precipitation appears after an agricultural drought, which would lead to a wetter surface soil but a dryer root zone soil. Under those conditions, the two-stage trapezoid could become invalid.

Thirdly, the TMEF couples the two-stage trapezoidal space with the Priestly-Taylor formula to simulate $\mathrm{EF}_{\mathrm{V}}, \mathrm{EF}_{\mathrm{s}}$, and $\mathrm{EF}$ in a two-source scheme. It is well known that the rate of ET is mainly controlled by the available energy, the availability of water, and other factors affecting the mechanism to transport water from the land surface to the atmosphere. The Priestly-Taylor formula and its extension grasp this feature since LE is expressed as the product of available energy $\left(R_{n}-G\right)$, available water $(\phi)$, and other factors $(\Delta / \Delta+\gamma)$. Many one-source models use the triangular LST/FVC space to obtain the $\phi$ value. In contrast, the TMEF model uses the two-stage trapezoidal space to obtain the $\phi$ value, which facilitates modeling and partitioning ET.

Additionally, the TMEF has some common advantages with the models that are based on LST/FVC space. For example, it has simple calculation form and enables calculating EF from a remote sensing image itself without any additional information. Certainly, some meteorological parameters which are difficult to obtain by remote sensing are used in this study to determine the theoretical dry and wet edges, such as the $u_{*}$ and $T_{\mathrm{a}}$. However, the theoretical boundaries can be acquired approximately by the image itself in arid and semi-arid regions [3].

In our previous paper [19], the conventional trapezoid in TTME model was just substituted with the two-stage trapezoid and the TTME model based on conventional trapezoid was compared with that based on two-stage trapezoid to demonstrate the validity of the two-stage trapezoid. It is noteworthy that the proposed TMEF model in this study is different from the TTME model based on two-stage trapezoid, because the TMEF has the abovementioned unique advantages. Even for the two-stage trapezoid model, this study is an improvement of the paper in [19] since we improve the determination of the wet edge. Evaluation results in Figures 3 and 4 indicate that the TMEF model 
presents the best effectiveness in estimating EF as compared with the TTME and the OTEF models at each and all of the sites. Moreover, Figure 5 shows that the TMEF model is more effective than the TTME in partitioning EF. In summary, by right of its unique advantages, the TMEF model advances the performances in modeling and partitioning EF or ET based on LST/FVC space.

Certainty, there are some limitations in the suggested model. Firstly, the TMEF model is constrained to work under clear sky conditions because it uses the remotely sensed LST to estimate EF [13,38,39]. Secondly, the LST/FVC space depends on the assumption that LST and FVC have negative relationship. Some previous studies indicated that when water is the limiting factor for vegetation growth, the LST has a negative correlation with NDVI. However, a positive LST-NDVI correlation exists when energy is the limiting factor for vegetation growth [40-42]. Therefore, the TMEF model is suggested to the areas and periods where water is the limiting factor for vegetation growth, such as in arid and semi-arid areas and during the midseason. Additionally, model sensitivity analysis indicates that the TMEF is more sensitive to the input variables in the environment that vegetation suffers water stress. For example, a $2 \mathrm{~K}$ increase in LST would result in a 57.04\% decrease in EF estimates in that environment. Therefore, the TMEF requires higher data quality of the input variables for the area where vegetation suffers water stress.

\section{Conclusion}

In this study, we present a two-source model for estimating EF, named TMEF, through coupling the two-stage trapezoidal LST/FVC space with the Priestly-Taylor formula. We also present a theoretical expression of the wet edge of LST/FVC space which was usually set to $T_{\mathrm{a}}$ or the lowest LST value in an image. The TMEF model was evaluated by comparing with EF observations at six eddy covariance system sites located in Zhangye oasis in the middle reaches of the Heihe River Basin, China. It was also compared with other two models that are based on conventional trapezoidal LST/FVC space. MODIS LST and NDVI products as well as some meteorological data during the period from June to September in 2012 were utilized in this study. Evaluation results indicate that the TMEF model outperforms the other two models in simulating EF and its partitioning. EF RMSE, $r$, and MARD are $0.10 \%, 0.69 \%$, and $9.57 \%$ for TMEF, $0.15 \%, 0.46 \%$, and $15.03 \%$ for TTME, and $0.27 \%, 0.62 \%$, and $30.49 \%$ for OTEF. Sensitivity analysis indicates that the TMEF model is most sensitive to LST and $T_{\mathrm{a}}$. A $2 \mathrm{~K}$ increase in LST and $T_{\mathrm{a}}$ would result in a 5.60\% decrease and a 7.92\% increase in EF estimates when vegetation is not subjected to water stress, and would result in a $57.04 \%$ decrease and a $53.66 \%$ increase when vegetation suffers water stress. This study provides a feasible way to advance the performances in estimating and partitioning EF or ET based on LST/FVC space.

Acknowledgments: This study is supported by the National Natural Science Fund of China (41501457). The author would like to thank Cold and Arid Regions Science Data Center at Lanzhou, China and Heihe Plan Science Data Center, National Natural Science Foundation of China for providing meteorological and eddy covariance system observations. Thanks are also expressed to NASA Land Processes Distributed Active Archive Center for providing the MODIS data.

Conflicts of Interest: The authors declare no conflict of interest.

\section{References}

1. Yang, J.X.; Wang, Y.P. Estimating evapotranspiration fraction by modeling two-dimensional space of NDVI/albedo and day-night land surface temperature difference: A comparative study. Adv. Water Resour. 2011, 34, 512-518. [CrossRef]

2. Wang, K.C.; Dickinson, R.E. A review of global terrestrial evapotranspiration: Observation, modeling, climatology, and climatic variability. Rev. Geophys. 2012, 50. [CrossRef]

3. Tang, R.; Li, Z.-L.; Tang, B. An application of the TS-VI triangle method with enhanced edges determination for evapotranspiration estimation from MODIS data in arid and semi-arid regions: Implementation and validation. Remote Sens. Environ. 2010, 114, 540-551. [CrossRef] 
4. $\quad$ Li, Z.L.; Tang, R.L.; Wan, Z.M.; Bi, Y.Y.; Zhou, C.H.; Tang, B.H.; Yan, G.J.; Zhang, X.Y. A review of current methodologies for regional evapotranspiration estimation from remotely sensed data. Sensors 2009, 9, 3801-3853. [CrossRef] [PubMed]

5. Hu, Z.; Yu, G.; Zhou, Y.; Sun, X.; Li, Y.; Shi, P.; Wang, Y.; Song, X.; Zheng, Z.; Zhang, L.; et al. Partitioning of evapotranspiration and its controls in four grassland ecosystems: Application of a two-source model. Agric. For. Meteorol. 2009, 149, 1410-1420. [CrossRef]

6. Wang, K.C.; Li, Z.Q.; Cribb, M. Estimation of evaporative fraction from a combination of day and night land surface temperatures and NDVI: A new method to determine the priestley-taylor parameter. Remote Sens. Environ. 2006, 102, 293-305. [CrossRef]

7. Peng, J.; Liu, Y.; Zhao, X.; Loew, A. Estimation of evapotranspiration from MODIS TOA radiances in the poyang lake basin, China. Hydrol. Earth Syst. Sci. 2013, 17, 1431-1444. [CrossRef]

8. Jiang, L.; Islam, S. Estimation of surface evaporation map over southern great plains using remote sensing data. Water Resour. Res. 2001, 37, 329-340. [CrossRef]

9. Cragoa, R.; Brutsaert, W. Daytime evaporation and the self-preservation of the evaporative fraction and the bowen ratio. J. Hydrol. 1996, 178, 241-255. [CrossRef]

10. Ma, Y.M.; Song, M.H.; Ishikawa, H.; Yang, K.; Koike, T.; Jia, L.; Meneti, M.; Su, Z.B. Estimation of the regional evaporative fraction over the tibetan plateau area by using Landsat-7 ETM data and the field observations. J. Meteorol. Soc. Jpn. 2007, 85A, 295-309. [CrossRef]

11. Jiang, L.; Islam, S.; Guo, W.; Jutla, A.S.; Senarath, S.U.S.; Ramsay, B.H.; Eltahir, E.A.B. A satellite-based daily actual evapotranspiration estimation algorithm over South Florida. Glob. Planet. Chang. 2009, 67, 62-77. [CrossRef]

12. Carlson, T. An overview of the "triangle method" for estimating surface evapotranspiration and soil moisture from satellite imagery. Sensors 2007, 7, 1612-1629. [CrossRef]

13. Yang, Y.T.; Long, D.; Guan, H.D.; Liang, W.; Simmons, C.; Batelaan, O. Comparison of three dual-source remote sensing evapotranspiration models during the Musoexe-12 campaign: Revisit of model physics. Water Resour. Res. 2015, 51, 3145-3165. [CrossRef]

14. Jiang, L.; Islam, S. A methodology for estimation of surface evapotranspiration over large areas using remote sensing observations. Geophys. Res. Lett. 1999, 26, 2773-2776. [CrossRef]

15. Stisen, S.; Sandholt, I.; Norgaard, A.; Fensholt, R.; Jensen, K.H. Combining the triangle method with thermal inertia to estimate regional evapotranspiration-Applied to MSG-SEVIRI data in the Senegal River basin. Remote Sens. Environ. 2008, 112, 1242-1255. [CrossRef]

16. Nishida, K.; Nemani, R.R.; Running, S.W.; Glassy, J.M. An operational remote sensing algorithm of land surface evaporation. J. Geophys. Res.-Atmos. 2003, 108, 4270. [CrossRef]

17. Long, D.; Singh, V.P. A two-source trapezoid model for evapotranspiration (TTME) from satellite imagery. Remote Sens. Environ. 2012, 121, 370-388. [CrossRef]

18. Yang, Y.; Shang, S. A hybrid dual-source scheme and trapezoid framework-based evapotranspiration model (HTEM) using satellite images: Algorithm and model test. J. Geophys. Res. Atmos. 2013, 118, 2284-2300. [CrossRef]

19. Sun, H. Two-stage trapezoid: A new interpretation of the surface temperature and fractional vegetation cover space. IEEE J. Sel. Top. Appl. Earth Obs. Remote Sens. 2016. In press. [CrossRef]

20. Sandholt, I.; Rasmussen, K.; Andersen, J. A simple interpretation of the surface temperature/vegetation index space for assessment of surface moisture status. Remote Sens. Environ. 2002, 79, 213-224. [CrossRef]

21. Priestley, C.H.B.; Taylor, R.J. On the assessment of surface heat flux and evaporation using large-scale parameters. Mon. Weather Rev. 1972, 100, 81-92. [CrossRef]

22. Carlson, T.N. Triangle models and misconceptions. Int. J. Remote Sens. Appl. 2013, 3, 155-158.

23. Singh, R.K.; Irmak, A. Treatment of anchor pixels in the metric model for improved estimation of sensible and latent heat fluxes. Hydrol. Sci. J.-J. Sci. Hydrol. 2011, 56, 895-906. [CrossRef]

24. Eichinger, W.E.; Parlange, M.B.; Stricker, H. On the concept of equilibrium evaporation and the value of the priestley-taylor coefficient. Water Resour. Res. 1996, 32, 161-164. [CrossRef]

25. Lhomme, J.-P. A theoretical basis for the priestley-taylor coefficient. Bound.-Layer Meteorol. 1997, 82, $179-191$. [CrossRef]

26. Long, D.; Singh, V.P.; Scanlon, B.R. Deriving theoretical boundaries to address scale dependencies of triangle models for evapotranspiration estimation. J. Geophys. Res.-Atmos. 2012, 117, 1-17. [CrossRef] 
27. Li, X.; Li, X.W.; Li, Z.Y.; Ma, M.G.; Wang, J.; Xiao, Q.; Liu, Q.; Che, T.; Chen, E.X.; Yan, G.J.; et al. Watershed allied telemetry experimental research. J. Geophys. Res.-Atmos. 2009, 114. [CrossRef]

28. Liu, S.M.; Xu, Z.W.; Wang, W.Z.; Jia, Z.Z.; Zhu, M.J.; Bai, J.; Wang, J.M. A comparison of eddy-covariance and large aperture scintillometer measurements with respect to the energy balance closure problem. Hydrol. Earth Syst. Sci. 2011, 15, 1291-1306. [CrossRef]

29. Ma, Y.F.; Liu, S.M.; Zhang, F.; Zhou, J.; Jia, Z.Z.; Song, L.S. Estimations of regional surface energy fluxes over heterogeneous oasis-desert surfaces in the middle reaches of the Heihe River during HiWATER-Musoexe. IEEE Geosci. Remote Sens. Lett. 2015, 12, 671-675.

30. Xu, Z.; Liu, S.; Li, X.; Shi, S.; Wang, J.; Zhu, Z.; Xu, T.; Wang, W.; Ma, M. Intercomparison of surface energy flux measurement systems used during the HiWATER-Musoexe. J. Geophys. Res.-Atmos. 2013, 118, 13140-13157. [CrossRef]

31. Liu, S.M.; Xu, Z.W.; Zhu, Z.L.; Jia, Z.Z.; Zhu, M.J. Measurements of evapotranspiration from eddy-covariance systems and large aperture scintillometers in the Hai River Basin, China. J. Hydrol. 2013, 487, 24-38. [CrossRef]

32. Li, X.; Cheng, G.; Liu, S.; Xiao, Q.; Ma, M.; Jin, R.; Che, T.; Liu, Q.; Wang, W.; Qi, Y.; et al. Heihe watershed allied telemetry experimental research (HiWATER): Scientific objectives and experimental design. Bull. Am. Meteorol. Soc. 2013, 94, 1145-1160. [CrossRef]

33. Xu, Z.W.; Liu, S.M.; Li, X.; Shi, S.J.; Wang, J.M.; Zhu, Z.L.; Xu, T.R.; Wang, W.Z.; Ma, M.G. Intercomparison of surface energy flux measurement systems used during the HiWATER-Musoexe. J. Geophys. Res.-Atmos. 2013, 118, 13140-13157. [CrossRef]

34. Sun, H.; Chen, Y.; Gong, A.; Zhao, X.; Zhan, W.; Wang, M. Estimating mean air temperature using modis day and night land surface temperatures. Theor. Appl. Climatol. 2014, 118, 81-92. [CrossRef]

35. Sun, H.; Chen, Y.; Zhan, W. Comparing surface and canopy layer urban heat islands over Beijing using MODIS data. Int. J. Remote Sens. 2015, 36, 5448-5465.

36. Sun, J.; Hu, Z.-Y.; Xun, X.-Y.; Peng, W.; LÜ, B.; Xu, L.-J. Albedo characteristics in different underlying surfaces in mid and upper-reaches of Heihe and its impact factor analysis. Plateau Meteorol. 2011, 30, 607-613. (In Chinese)

37. Walker, W.R.; Skogerboe, G.V. Surface Irrigation: Theory and Practice; Prentice Hall College Div: Englewood Cliffs, NJ, USA, 1987.

38. Long, D.; Longuevergne, L.; Scanlon, B.R. Uncertainty in evapotranspiration from land surface modeling, remote sensing, and grace satellites. Water Resour. Res. 2014, 50, 1131-1151. [CrossRef]

39. Long, D.; Yang, Y.; Wada, Y.; Hong, Y.; Liang, W.; Chen, Y.; Yong, B.; Hou, A.; Wei, J.; Chen, L. Deriving scaling factors using a global hydrological model to restore grace total water storage changes for China's Yangtze River basin. Remote Sens. Environ. 2015, 168, 177-193. [CrossRef]

40. Karnieli, A.; Bayasgalan, M.; Bayarjargal, Y.; Agam, N.; Khudulmur, S.; Tucker, C.J. Comments on the use of the vegetation health index over Mongolia. Int. J. Remote Sens. 2006, 27, 2017-2024. [CrossRef]

41. Karnieli, A.; Agam, N.; Pinker, R.T.; Anderson, M.; Imhoff, M.L.; Gutman, G.G.; Panov, N.; Goldberg, A. Use of NDVI and land surface temperature for drought assessment: Merits and limitations. J. Clim. 2010, 23, 618-633. [CrossRef]

42. Sun, H.; Zhao, X.; Chen, Y.; Gong, A.; Yang, J. A new agricultural drought monitoring index combining MODIS NDWI and day-night land surface temperatures: A case study in china. Int. J. Remote Sens. 2013, 34, 8986-9001. [CrossRef]

(C) 2016 by the author; licensee MDPI, Basel, Switzerland. This article is an open access article distributed under the terms and conditions of the Creative Commons by Attribution (CC-BY) license (http://creativecommons.org/licenses/by/4.0/). 